\title{
La perfección del contrato en Internet según el ordenamiento jurídico español. Especial referencia al caso de las páginas web
}

The Perfection of Contracts Through Internet According to the Spanish Legislation. Special Reference to the Case of Web Pages

GABRIELA OBREGÓN SIEGMUND *

Universidad de Barcelona

RECEPCIÓN: IO/O7/20I2·ACEPTACIÓN: I3/II/2OI2

RESUMEN En el presente trabajo intentaremos realizar un análisis de la problemática surgida luego de la modificación introducida por la Ley de Servicios de la Sociedad de la Información y Comercio Electrónico a los artículos I 262 del Código Civil y 54 del Código de Comercio, relativa a la determinación del momento y lugar de la perfección de los contratos a distancia, específicamente, los contratos electrónicos.

PALABRAS CLAVE Contrato a distancia, contrato electrónico, página web, perfección del contrato, dispositivo automático.

ABSTRACT In this paper, we will try to make an analysis of the problems arose after the modification by the «Ley de Servicios de la Sociedad de la Información y Comercio Electrónico ( «Public Law I 3 of November, 20 I 2, the

* Abogada y alumna del Máster en Derecho de la Empresa y los Negocios de la Universidad de Barcelona, España. E-mail: gobregsi9@alumnes.ub.edu. 
Information Society and Electronic Commerce Act») to the articles I262 of the Civil Code and 54 of the Commercial Code, related to the determination of time perfection, at distance contracts, specifically, electronic contracts.

KEYWORDS Distance contract, electronic contract, web page, perfection of the contract, automatic device.

\section{La contratación a distancia}

1. La contratación entre presentes y entre ausentes. Su relación frente al concepto de contrato a distancia

Es evidente que el uso de internet posee la ventaja fundamental de permitir agilizar la conclusión de contratos celebrados entre partes físicamente no presentes, gracias a la celeridad misma del sistema, lo que le convierte en un medio de comunicación idóneo para la celebración de aquellos contratos que, bajo la nomenclatura comunitaria, suelen denominarse como «contratos a distancia».

Para iniciar el análisis del tema que nos ocupa, consideramos fundamental esclarecer la distinción de los denominados contratos entre presentes y aquellos celebrados entre ausentes, recordando además, una clasificación de los contratos en atención al modo que tienen de perfeccionarse, nos referimos, a los denominados de formación instantánea y de formación sucesiva.

Siguiendo a Menéndez, en principio, podría afirmase que los «contratos entre presentes» están representados por todos aquellos contratos que, en el supuesto en que las partes así lo quieran, pueden perfeccionarse de manera inmediata ${ }^{1}$. Así, según el mismo autor, los contratos entre presentes se identificarían con aquellos que tienen la virtualidad de formarse instantáneamente; pero se debe dejar en claro que son las partes las que optarán entre la formación instantánea o bien, dejarán que la fase precontractual se prolongue en el tiempo, en aras de una mayor reflexión o deliberación acerca de su conveniencia.

Por su parte, y siguiendo el mismo criterio, cabría identificar «contratos entre ausentes» con aquellos que necesariamente precisan de un intervalo determinado de tiempo para su formación, debido a la situación de no presencia de las partes ${ }^{2}$.

\footnotetext{
I. MENÉNDEZ (2005) p. 279.

2. Ídem, p. 280.
} 
Pues bien, luego de estas primeras aproximaciones, es importante clarificar dos cuestiones: la referente al medio de comunicación empleado para la celebración del contrato y qué se debe entender por intervalo de tiempo relevante.

Las partes pueden emplear distintos medios de comunicación para transmitir una aceptación contractual, entre las que se destacaron tradicionalmente hasta hace un tiempo la correspondencia postal, el telégrafo, el teléfono, la radio, el télex y el fax, pero hoy necesariamente debemos agregar, el correo electrónico, el chat, la videoconferencia, los servicios de mensajería entre teléfonos, aquellos que se suceden entre móviles de tercera generación, la página web, etc. Obviamente, por su trascendencia en la vida moderna el estudio lo centraremos en aquellos medios de comunicación entre ordenadores y específicamente en las páginas web.

Por intervalo de tiempo relevante, Menéndez entiende:

aquel espacio de tiempo que separa la emisión de la aceptación contractual por parte del destinatario de la previa oferta y el conocimiento que de ésta tenga el oferente, y durante el cual el autor de la aceptación pueda realizar determinadas actuaciones tendientes precisamente a dejarla sin valor o eficacia; es decir, tendientes a la retirada de la aceptación ${ }^{3}$.

Ahora, la pregunta que surge es si toda contratación entre ausentes supone una formación sucesiva del contrato. Para responderla, ha de definirse lo que debe entenderse por «formación sucesiva». El profesor Menéndez considera que resulta más exacto el empleo de la expresión «formación ex intervallo temporis» del contrato como antagónico al de «formación instantánea», reservando el uso del término «formación sucesiva» para uno de los posibles supuestos de contratación ex intervallo temporis.

De este modo, el contrato de formación instantánea sería aquél cuya fase precontractual se ha reducido al simple intercambio inmediato de la oferta y la aceptación. En cambio, la formación ex intervallo temporis se identifica con todo contrato que previamente a su nacimiento ha tenido una fase precontractual prolongada en el tiempo. Dicha dilación temporal puede tener su origen básicamente en dos causas:

- Que el contrato no sea fruto del mero intercambio oferta-aceptación, sino que, con anterioridad a éste se hayan realizado una multitud varia-

3. Ibidem. 
da de actos precontractuales. Este tipo de contratos ex intervallo temporis podrían recibir, en un sentido estricto, la denominación de «contratos de formación sucesiva o progresiva».

- O bien, pese a ser transmitidas simplemente la oferta y la aceptación —sin haberse realizado acto alguno anterior o posterior, voluntario o necesario-, debido a la situación de ausencia de las partes, se produce un intervalo temporal que separa el teórico concurso inmediato entre la oferta y la aceptación. Este último tipo de contrato ex intervallo temporis se identificaría con los contratos celebrados entre partes ausentes o no presentes ${ }^{4}$.

Lo que hemos querido intentar en las líneas precedentes es que el lector, a través de la clasificación expuesta, adopte una visión global del fenómeno formativo contractual, siempre teniendo presente la importancia de tal distinción referente a la determinación del momento de perfección de los contratos.

Ahora bien, teniendo claro que la clasificación de contratos entre presentes y entre ausentes se basa principalmente en un criterio temporal, es preciso relacionar esta clasificación con la denominada «contratación a distancia».

Hasta hace un tiempo, la doctrina confundía las expresiones "contrato entre ausentes» y "contrato a distancia», considerándolos idénticos y contrapuestos a los contratos entre presentes, cuestión que es entendible en cierto modo, sobre todo teniendo en consideración que la nomenclatura de contratación a distancia es más reciente y se ha introducido principalmente a través de la legislación comunitaria ${ }^{5}$.

4. MENÉNDEZ (2005) p. 28 I-282.

5. En el ámbito comunitario destacan la Directiva 97/7/CE relativa a la protección de los consumidores en materia de contratos a distancia y más recientemente la Directiva 20I I/83/UE del Parlamento Europeo y del Consejo, de 25 de octubre de 20I I, sobre los derechos de los consumidores, que aunque aún no se encuentra traspuesta en el ordenamiento jurídico español, es de vital importancia pues se encarga de definir qué se entiende por «contrato a distancia». En España merecen ser nombradas la actual Ley de Ordenación del Comercio Minorista reformada por la Ley 47/2002 y el RDL I/2007 por el que se aprueba el texto refundido de la Ley General para la Defensa de los Consumidores y Usuarios, cuando regulan las «ventas a distancia» restringiendo el concepto de contrato a distancia — que hasta hace un tiempo se identificaba con contrato entre ausentes o partes no presentes - a aquel que se perfecciona sin la presencia física simultánea de las partes; por lo que el calificativo de "presencia» adopta un carácter exclusivamente geográfico. 
Sin embargo, hoy no se justificaría tal confusión. La contratación a distancia atiende a un criterio geográfico o espacial. Contrato a distancia es aquel que se realiza sin la presencia física simultánea de las partes y en el que se han utilizado una o más técnicas de comunicación a distancia hasta el momento en que se celebra el contrato y en la propia celebración del mismo.

Clarificando, contrato a distancia sería aquel en el que la transmisión de al menos- la aceptación contractual tiene lugar entre partes que no se hallan de modo simultáneo físicamente presentes. Como puede notarse, contrato a distancia y contrato entre ausentes son categorías diferentes. La categoría de contrato entre ausentes es más reducida que la de contrato a distancia (de la cual forma parte), por lo que no serían contratos entre ausentes los que se concluyen, pese a encontrarse las partes físicamente distantes, mediante el empleo de un medio técnico que permite una comunicación instantánea. Estos últimos serían, según lo expuesto recientemente, contratos entre presentes. El ejemplo más claro de lo que estamos explicando lo podemos ilustrar con el caso de la contratación que se realiza mediante teléfono. Evidentemente se trata de un caso de contratación a distancia pues geográficamente las partes se encuentran en lugares distintos, pero no es un contrato entre ausentes, sino entre presentes pues existe inmediatez en la formación del consentimiento, es decir, no media un intervalo de tiempo relevante entre la manifestación de la aceptación y el conocimiento que de esta toma el oferente, es un contrato de formación instantánea ${ }^{6}$. De idéntico modo a como sucede con el teléfono acontece con el uso del chat o videoconferencia. Ambos medios permiten comunicarse a las partes de idéntica forma a la presencia física, por lo queda excluida la posibilidad de que entre la emisión de la aceptación y su conocimiento por el destinatario medie un intervalo temporal relevante.

Por tanto, y para cerrar este apartado, vale recalcar que el contrato a distancia puede ser contrato entre ausentes o entre presentes, dependerá de si es

6. STS español de 5 de enero de I948. El Tribunal Supremo Español ha establecido claramente en esta sentencia que la contratación telefónica es un caso de contratación entre presentes. En concreto señaló que el acuerdo alcanzado durante una conversación telefónica daba lugar al perfeccionamiento del contrato, lo mismo que se hubiera concertado entre presentes. En el mismo sentido, PINOCHET (2005), p. 273-302. Manifiesta que igual criterio es seguido en los países del common law y, específicamente, en Estados Unidos e Inglaterra, países en los que los contratantes que se comunican por teléfono son considerados «presentes». 
o no necesario que medie un intervalo de tiempo para que éste se perfeccione. Hace unos años atrás se solía sostener que el contrato a distancia era en su gran mayoría un contrato entre ausentes pero hoy esta situación ha cambiado sustancialmente debido al uso de las tecnologías que aceleran todos los procesos y obviamente dotan a la contratación de cierta inmediatez, impensada hace un par de décadas.

\section{Contratación electrónica}

\section{Marco jurídico regulador}

$\mathrm{Al}$ respecto, lo primero que debemos tener presente es que el documento que sentó las bases para el tratamiento de este tema y dio origen a su posterior regulación fue la Ley Modelo de la CNUDMI-UNCITRAL sobre Comercio Electrónico, de 1998.

En el ámbito comunitario la normativa clave se establece en la Directiva 2000/3 I/CE del Parlamento Europeo y del Consejo, de 8 de junio, relativa a determinados aspectos jurídicos de los servicios de la sociedad de la información, en particular el comercio electrónico en el mercado interior (Directiva sobre comercio electrónico). Ésta pretendió dotar de una cierta armonía al conjunto normativo que se encontraba disperso hasta ese entonces. De hecho, suele afirmarse que la finalidad última de la Unión Europea es alcanzar un marco jurídico único y coherente en todo el espacio de la Unión.

Es necesario mencionar igualmente a una nueva Directiva que aún no se encuentra incorporada al ordenamiento jurídico español; nos referimos a la Directiva $20 \mathrm{II} / 83 / \mathrm{UE}$ del Parlamento Europeo y del Consejo, de 25 de octubre de 20II, sobre los derechos de los consumidores, por la que se modifican la Directiva 93/I3/CEE del Consejo y la Directiva I999/44/CE del Parlamento Europeo y del Consejo y se derogan la Directiva $85 / 577 /$ CEE del Consejo y la Directiva 97/7/CE del Parlamento Europeo y del Consejo. En ella se regulan ciertos aspectos de los contratos celebrados a distancia, específicamente el deber de información al consumidor y el derecho de desistimiento que le asiste en este tipo de contratación. La incorporación de esta Directiva (que es de armonización plena) al ordenamiento jurídico español supondrá, evidentemente, la modificación de, a lo menos, el Texto Refundido de la Ley General para la Defensa de los Consumidores y Usuarios.

A nivel nacional, el marco normativo está encabezado por la Ley 34/2002, 
de i a de julio, de Servicios de la Sociedad de la Información y Comercio Electrónico (en adelante LSSICE), que expresamente se encarga de regular la contratación por vía electrónica.

Debemos incluir aquí a la Ley 2I/20 I I, de 26 de julio, de Dinero Electrónico y la Ley 53/2003, de I 9 de diciembre, de Firma Electrónica, por su estrecha relación con el tema.

Considerando que la contratación electrónica es un tipo de contratación a distancia, se le debe aplicar, de igual forma, la normativa de esta materia. Así, resulta de suma trascendencia la aplicación del Real Decreto Legislativo I/2007, de I 6 de noviembre, por el que se aprueba el texto refundido de la Ley General para la Defensa de los Consumidores y Usuarios (en adelante TRLGDCU), cuyo Título III se encarga de regular los contratos celebrados a distancia en los que interviene un consumidor. Asimismo, la Ley 7/1996, de I 5 de enero, de Ordenación del Comercio Minorista (en adelante LOCM), reformada por la Ley 47/2002 y que se encuentra vigente aún para regular las ventas a distancia en donde no exista la intervención de un consumidor, resulta de aplicación a la contratación electrónica. Además de las ya mencionadas se debe sumar a lista, por ser reguladora de la contratación a distancia, la Ley 22/2007, de I I de julio sobre Comercialización a Distancia de Servicios Financieros Destinados a los Consumidores.

En el plano sectorial, la normativa aplicable se compone de la Ley I6/2009, de 13 de noviembre, de Servicios de Pago, Ley Orgánica I 5/I999, de I 3 de diciembre, sobre Protección de Datos, Ley 32/2003, de 3 de noviembre, General de Telecomunicaciones, el RDL I/I996, de I2 de abril, por el que se aprueba el texto refundido sobre Propiedad Intelectual, modificado para la realidad digital por Ley 23/2006, de 7 de julio, Ley 34/1988, General de Publicidad, adaptada a su específico perfil, Ley 7/I988, de I 3 de abril sobre Condiciones Generales de la Contratación y, en todo caso, la ley civil y mercantil que resulte aplicable.

\section{El contrato electrónico. Concepto y características}

Habiendo ya establecido el marco jurídico regulador de la contratación a distancia, nos corresponde adentrarnos en el concepto de contrato electrónico y sus características. Lo primero que debemos dejar claro, tal y como sostiene Vega, es que los contratos celebrados electrónicamente, no representan una nueva modalidad de contratos, sino que siguen siendo los tradicionales pero 
ahora celebrados por medios electrónicos, esto es lo que determina su singularidad $^{7}$. En el mismo sentido de Barral $^{8}$.

Como señala Barral, la LSSICE no es excesivamente precisa a la hora de tratar lo que puede entenderse como contrato realizado por medios electrónicos, pues en el título se refiere al «comercio electrónico», mientras que en la Exposición de Motivos y en el articulado se refiere a la "contratación electrónica» o directamente a su resultado, es decir, los «contratos formalizados por vía electrónica» o simplemente, los «contratos electrónicos». De todas formas, apunta la autora, la idea de contratación electrónica parece más limitada que la de comercio electrónico, pues sólo se referiría a aquellos intercambios electrónicos en los que se realiza un contrato, mientras que comercio electrónico englobaría también todos los aspectos previos: publicidad, oferta y los de ejecución del contrato y servicios de posventa ${ }^{9}$.

Unido a lo anterior, podemos percatarnos que a menudo se suele verificar una cierta imprecisión en el uso del lenguaje referente a esta materia y sobre todo una falta de uniformidad, pues es posible encontrarse con expresiones tales como contrato informático, contrato telemático, contrato on line o contrato digital como sinónimos del denominado contrato electrónico. Ésta es una característica común a toda la literatura jurídica que se produce en torno a la revolución tecnológica e informática de los últimos años. Sin perjuicio de aceptar que las denominaciones se utilicen indistintamente, no debemos confundirnos, hoy en día el concepto de contrato electrónico se encuentra más delimitado ${ }^{10}$.

7. VEGA (2005) p. 224.

8. BARRAL (2003) sostiene que el rasgo identificador de la contratación electrónica atiende al medio en el que esa contratación se desarrolla y no a los sujetos que participan en ella. No se trata, a su vez, de una nueva modalidad contractual sino de contratos calificados por razón del medio en que se realizan.

9. BARRAL (2007).

Io. Para Menéndez, la expresión más comprensiva de todas sería la de "contrato vía Internet» pues se trata de un contrato electrónico, además de ser on line o en línea por excelencia, cuyo objeto puede ser o no un bien o servicio informático —en el caso en que lo sea también será un servicio informático-, que puede concluirse entre partes que están o no presentes - por lo que no necesariamente se tratará de un contrato a distancia, ni de un contrato telemático-, pero que si tiene lugar entre partes que no están presentes tendrá el calificativo de contrato telemático, y además si en su conclusión se emplea la firma digital será también un contrato digital. 
En España, la LSSICE define en la letra h) del anexo al «contrato celebrado por vía electrónica» o «contrato electrónico» como «todo contrato en el que la oferta y la aceptación se transmiten por medio de equipos electrónicos de tratamiento y almacenamiento de datos, conectados a una red de telecomunicaciones ${ }^{11}$.

Es importante relacionar lo anterior con lo que dispone la letra a) del anexo de la misma ley, pues de su lectura parece desprenderse que la contratación operada por fax o télex debe quedar excluida de la regulación sobre contratos electrónicos, no por no celebrarse a través de procedimientos electrónicos, sino porque la comunicación por estos medios no constituye un «servicio de la sociedad de la información» ${ }^{12}$. Barral, en el mismo sentido, sostiene que se debería añadir a este tipo de contratación los medios electrónicos tradicionales como el teléfono o telégrafo pero asume, esta vez apoyada en la opinión de Gramunt Fombuena, «que las nociones de contratación electrónica y de servicios de la sociedad de la información no coinciden exactamente, por lo que es posible hallar supuestos de contratos materialmente electrónicos, según la definición propuesta, que escapan del ámbito de definición de la LSSICE» ${ }^{13}$.

$\mathrm{Al}$ parecer, el adjetivo «electrónico» reduce su aplicación a la existencia de tratamiento o almacenamiento de datos, y esto no lo hace ni el fax ni el télex ni el teléfono. Pero ello no significa que no sean medios de comunicación electrónico. A nuestro juicio lo son, por lo que en sentido genérico también son

I I. Un primer acercamiento a este concepto lo encontramos en la Ley Modelo de la CNUDMI-UNICITRAL sobre Comercio Electrónico (I998), que en relación con la formación y validez de los contratos, señala en su artículo I I: «En la formación de un contrato, de no convenir las partes otra cosa, la oferta y su aceptación podrán ser expresadas por medio de un mensaje de datos. No se negará validez o fuerza obligatoria a un contrato por la sola razón de haberse utilizado en su formación un mensaje de datos...» Un segundo acercamiento lo hallamos en la Directiva 2000/3 I/CE, sobre Comercio Electrónico, donde en su artículo 9, referido a la formación y validez de los contratos, señala: «Los Estados miembros velarán porque su legislación permita la celebración de contratos por vía electrónica. Los Estados miembros garantizarán en particular que el régimen jurídico aplicable al proceso contractual no entorpezca la utilización real de los contratos por vía electrónica, ni conduzca a privar de efecto y de validez jurídica a este tipo de contratos en razón de su celebración por vía electrónica...».

I2. MENÉNDEZ (2005) p. I65.

I3. BARRAL (2005) p. I76. 
contratos electrónicos a los cuales, sin embargo, no cabe la aplicación de la LSSICE.

Entonces, para estar ante un contrato electrónico es determinante la exigencia de dos requisitos. Primero, la necesidad de que el medio de comunicación empleado permita no sólo la transmisión electrónica de datos, sino también, su almacenamiento o archivo y su tratamiento o procesamiento. Segundo, que la oferta y la aceptación se hayan comunicado por alguno de los medios electrónicos. No importa tanto que la ejecución del contrato no tenga lugar por vía electrónica, lo determinante es que la perfección de este contrato, es decir, la concurrencia de la oferta y la aceptación tengan lugar precisamente por vía electrónica. A esto debemos añadir dos datos más que caracterizan al contrato electrónico, como son la exigencia de una necesaria conexión de las partes a la red y la falta de presencia física de las partes, que no debe confundirse con la existencia o no de simultaneidad ${ }^{14}$, pues como veremos más adelante en ciertos contratos electrónicos la simultaneidad es inherente a ellos y en otros no.

En cuanto a las categorías de contratos electrónicos que existen, podemos mencionar a aquel celebrado mediante correo electrónico, página web, chat o fórum de diálogo, videoconferencia, mensajería instantánea de móviles de tercera generación y subasta electrónica. En sentido estricto, y tal como lo señalamos en líneas precedentes, deberían quedar incorporados en este concepto aquellos contratos celebrados por los medios electrónicos tradicionales como el teléfono o el télex, sin embargo, escapan a la aplicación de la LSSIC y, por tanto, escapan también al objetivo del presente estudio.

Finalmente, y para ir siguiendo la línea trazada al comienzo de este trabajo, diremos que, en base a un criterio geográfico, los contratos electrónicos son un subconjunto de los denominados contratos a distancia y que pueden, a su vez, según un criterio temporal, ser catalogados como contratos entre presentes (es el caso del chat, la videoconferencia o la página web activa) o entre ausentes (como el correo electrónico y la mensajería de móviles de tercera generación) ${ }^{15}$.

\section{Los denominados agentes inteligentes}

No podemos dejar de referirnos en este apartado al tema de los denominados agentes inteligentes pues, posteriormente, volveremos a tratarlos cuan-

\footnotetext{
I4. BERROCAL (2009) p. 7.

I 5. En este sentido, GALÁN (2005) p. 203-228.
} 
do intentemos dilucidar el momento en que se perfecciona el contrato electrónico.

El ordenador está compuesto por un conjunto de mecanismos que comprenden material físico e intelectual. La parte material es el ordenador y sus accesorios (hardware), es decir, los circuitos electrónicos y dispositivos mecánicos que son la parte física tangible de la máquina. La parte intelectual o soporte lógico (software) es aquella formada por un conjunto de programas que determinan el funcionamiento del ordenador.

El agente inteligente o agente electrónico es una aplicación de un programa informático cuya ejecución permite al ordenador actuar respondiendo de modo automático ante un determinado hecho. Entonces, se puede definir al agente inteligente como programa de ordenador cuya aplicación permite responder de forma automática a mensajes electrónicos sin la intervención del titular del programa, si bien de su actuación se derivan consecuencias jurídicas para éste ${ }^{16}$.

Según las características de su programación, los agentes inteligentes se clasifican en las siguientes categorías:

- Agentes electrónicos de demanda (demand agent). Son aquellos cuya función consiste en contratar electrónicamente de forma automática, respondiendo a las ofertas recibidas de los clientes. El ordenador responde a las peticiones de los clientes, siempre que las ofertas que reciba se encuentren dentro de los límites máximos de contratación que han sido establecidos como parámetros en el programa.

- Agentes electrónicos de decisión (buying agent). Son aquellos que tras comprobar mediante la consulta continuada de la base de datos (feedback), que existe una determinada demanda, adquieren de forma automática los productos que necesitan.

- Agentes electrónicos de relación. Se emplean para mantener actividades de relación que también son realizadas en el comercio electrónico. La intervención del agente inteligente tiene como objetivo favorecer la relación entre los prestadores de servicios de la sociedad de la información y los usuarios de internet.

El uso de agentes inteligentes en el comercio electrónico cada día adquiere

I6. CAMACHO (2005) p. I33. 
mayor importancia. La contratación electrónica en la que intervienen tiene dos modalidades. Primero, contratación electrónica en que una de las partes es un agente inteligente mientras que la otra no lo es (proveedor o consumidor). Segundo, contratación electrónica entre agentes inteligentes. Esta última modalidad no está lejos de convertirse en una práctica habitual del comercio electrónico ${ }^{17}$.

\section{La perfección del contrato a distancia y en particular del contrato electrónico}

\section{Determinación del momento de perfección del contrato}

\section{Relevancia jurídica de la cuestión}

Evidentemente conocer con certeza el momento exacto en que se perfecciona un contrato - incluidos los que tienen lugar en la red- tiene una trascendencia de primer nivel. Siguiendo a Menéndez, ${ }^{18}$ esta determinación está íntimamente relacionada con los siguientes temas:

- El principal de todos es el hecho de representar el inicio o entrada en vigor del contrato que une a las partes durante un período determinado, más extenso de tratarse de una relación contractual de duración prolongada, y, en todo caso, convierte en directamente exigible por las partes las obligaciones por él instituidas.

- Ineficacia de los intentos extemporáneos de revocación y retirada de la oferta o retirada de la aceptación por parte de sus autores.

- Ineficacia de determinadas causas de extinción de las declaraciones contractuales (por ejemplo, incapacidad sobrevenida o muerte del autor de la declaración, caducidad, etcétera).

- Transmisión de los riesgos de la cosa al adquirente, en aquellos casos en que el contrato que se perfeccione conlleve la transmisión de la propiedad $\mathrm{u}$ otro derecho real.

- Determinación exacta de la ley o norma aplicable en el tiempo a la relación contractual creada, es decir, los problemas típicos asociados a la aplicación temporal de las normas jurídicas.

I7. CAMACHO (2005) p. I34-I35.

I 8. MENÉNDEZ (2005) p. 298. 
- Momento determinante del inicio del cómputo de determinados plazos para el correcto ejercicio de algunos derechos y acciones.

\section{Teorías para determinar el momento de perfección del contrato}

En el ordenamiento jurídico español el consentimiento de los contratantes es requisito fundamental para que el contrato nazca a la vida del derecho. Según determina el Código Civil en su artículo I254: «el contrato existe desde que una o varias personas consienten en obligarse, respecto de otra u otras a dar alguna cosa o prestar algún servicio». Por su parte, el artículo I 258 dispone «los contratos se perfeccionan por el mero consentimiento». Finalmente, el I262. I expresa: «el consentimiento se manifiesta por el concurso de la oferta y la aceptación sobre la cosa y la causa que han de constituir el contrato».

Así, el consentimiento se forma por el concurso de las declaraciones de voluntad de los contratantes, la oferta y la aceptación. Es preciso recordar que la oferta ha ser completa, debe tener un propósito serio e inequívoco de concluir un contrato, es decir, de quedar obligado y debe tener carácter recepticio. Por su parte, la aceptación debe cumplir con los requisitos de ser seria y definitiva, ir dirigida al oferente, coincidir en su contenido con la oferta y, por último, ser tempestiva. Cuando las partes están presentes no hay problema para determinar el momento y lugar de la perfección del contrato pues la aceptación será emitida y recogida casi simultáneamente. En cambio el problema surge cuando las partes no están físicamente presentes al mismo tiempo. En este tipo de contratación, sin la presencia física simultánea de las partes, por hallarse éstas en lugares distintos y emplear determinados medios de comunicación a distancia, existe una separación de tiempo entre la oferta y la aceptación ${ }^{19}$.

La determinación del momento de perfección del contrato a distancia ha sido objeto de especial atención por la doctrina que ha elaborado las teorías, que, en síntesis, expongo a continuación.

Teoría de la emisión, declaración o manifestación. Según esta teoría el contrato se perfecciona cuando la aceptación es emitida, es decir, cuando el destinatario de la oferta manifiesta, declara o exterioriza la aceptación. Esta teoría resulta favorable a los intereses del aceptante ${ }^{20}$.

Los partidarios de esta doctrina, como señala Berrocal, afirman que la cau-

I9. CAMACHO (2005) p. 29I.

20. BERROCAL (2009) p. 29. 
sa única que puede producir el vínculo es la voluntad del aceptante y no cabe que sea el mero conocimiento que de la aceptación tenga el proponente. Dejar la perfección a merced de la toma de conocimiento de la aceptación por parte del oferente supondría, según los defensores, consagrar la teoría del arrepentimiento en los contratos, lo cual resulta absurdo ya que nadie puede ir en contra de sus propios actos ${ }^{21}$.

Esta teoría, a juicio de Camacho, plantea varios inconvenientes. En primer lugar, deja al arbitrio del aceptante la perfección del contrato. La autora clarifica esta afirmación con un ejemplo clásico: la aceptación contenida en una carta queda en manos de su autor quien puede destruirla sin que nadie tenga conocimiento de su existencia. Semejante aceptación, agrega, se diferencia poco de una voluntad no manifestada exteriormente. En segundo lugar, esta teoría olvida que para la perfección del contrato se requiere que la declaración se dirija al otro contratante, que la aceptación es una declaración recepticia ${ }^{22}$. En el mismo sentido opina Díez-Picazo, pues aunque sostiene que se trata de una teoría rigurosamente consecuente con el punto de partida dogmático y posee la ventaja de la celeridad, los inconvenientes tan graves que pueden resultar de su aplicación la hacen sucumbir ${ }^{23}$.

Teoría de la cognición, del conocimiento o de la información. Postula que el contrato se entiende perfeccionado cuando la aceptación llega a conocimiento del oferente. Parte de la base del carácter recepticio de las declaraciones de voluntad. Por tanto, la concurrencia de voluntades que perfecciona el contrato sólo tiene lugar cuando el oferente conoce la aceptación sin haber revocado previamente la oferta.

No está tampoco exenta de críticas. Por un lado, la toma de conocimiento de la aceptación tiene lugar en el estricto ámbito subjetivo del oferente, no puede determinarse con certeza el momento de perfección del contrato pues no es fácil probar cuándo tuvo el oferente conocimiento de la aceptación. Podrá en todo caso acreditarse cuándo se envió, e incluso cuándo fue recibida por el destinatario, pero difícilmente se podrá determinar en qué momento la conoció el oferente ${ }^{24}$. Asimismo, su aplicación estricta podría producir resultados injustos ya que el oferente podría retrasar deliberadamente el conocimiento de

\footnotetext{
2I. Ídem.

22. CAMACHO (2005) p. 296.

23. DÍEZ-PICAZO (2007) p. 347.

24. BERROCAL (2009) p. 30.
} 
la aceptación después de haberla recibido, quedando la perfección del contrato a su sola voluntad, resultando entonces atentatorio del principio de igualdad de los contratantes y, además, incompatible con la aceptación tácita ${ }^{25}$.

Teoría de la expedición, remisión, comunicación o transmisión. Entiende que el contrato se perfecciona cuando el destinatario de la oferta expide su declaración de voluntad, es decir, se la envía diligentemente al oferente, empleando un medio de comunicación adecuado. Camacho sostiene que la emisión eficaz se produce cuando el aceptante haya hecho por su parte todo lo necesario para que llegue al proponente. Escribir la carta o instruir al mensajero no equivalen a declaraciones de aceptación pues es necesario un acto de transmisión como sería la partida del mensajero o el depósito de la carta o telegrama en las oficinas postales o telegráficas ${ }^{26}$.

Aunque presenta frente a la teoría de la emisión cierta ventaja probatoria, tampoco está ajena a las críticas. No parece muy razonable considerar perfeccionado el contrato por la mera expedición de la aceptación, cuando puede darse el caso extremo que por cualquier motivo no imputable al aceptante su declaración no haya sido recibida por el oferente, porque, por ejemplo, se extravió por el camino, y pese a ello éste se encontraría obligado sin poder tener noticia. Por su parte, aplicando esta teoría sería imposible al aceptante retirar su aceptación una vez que la ha expedido, lo que no resulta lógico pues, por ejemplo, la regulación postal permite al remitente la recuperación de la correspondencia antes de que llegue a su destinatario ${ }^{27}$.

Teoría de la recepción. Esta doctrina sitúa la perfección del contrato en el momento en el que la declaración de aceptación llega al proponente, esto es, alcanza su ámbito de control o círculo de intereses del oferente (por ejemplo, el domicilio o el establecimiento mercantil) con independencia de que tome o no conocimiento de ella.

Esta teoría es la que tiene mayor predicamento en la doctrina, es admitida por la Convención de Viena sobre Compraventa Internacional, los Principios Unidroit y por los Principios de Derecho Europeo de los Contratos en los que queda matizada por el criterio del conocimiento.

Pese a lo anterior, también es criticada. Hay quienes consideran absurdo entender formado el contrato por el mero hecho de que el proponente haya

25. Ídem.

26. CAMACHO (2005) p. 296-297.

27. BERROCAL (2009) p. 3 I. 
recibido noticia del destinatario, pese a no conocer el contenido de la misma, pues ésta puede expresar tanto la aceptación como la denegación de la propuesta $^{28}$. Otros agregan que la aceptación puede ser ignorada por el oferente por negligencia suya o sus auxiliares o sin que intervenga culpa alguna por su parte o por parte del aceptante ${ }^{29}$.

Regulación de la materia en el ordenamiento jurídico español. Problemática

Hechas las precisiones sobre las diferentes teorías que la doctrina ha planteado para determinar el momento en que se perfecciona un contrato a distancia, nos corresponde analizar de qué manera esta cuestión se encuentra regulada en el ordenamiento jurídico español.

Con anterioridad a la entrada en vigor de la LSSICE, el Código Civil español se pronunciaba a favor de la tesis de la cognición, ya que el artículo i 262 disponía lo siguiente: «El consentimiento se manifiesta por el concurso de la oferta y la aceptación sobre la cosa y la causa que han de constituir el contrato. La aceptación hecha por carta no obliga al que hizo la oferta sino desde que llegó a su conocimiento».

Por su parte, el Código de Comercio acogía para los contratos mercantiles la teoría de la emisión en su artículo 54: «Los contratos que se contesten por correspondencia quedarán perfeccionados desde que se conteste aceptando la propuesta o las condiciones con que ésta fuere modificada». La evidente contradicción entre ambos artículos se pretendía justificar con el argumento de la celeridad que era necesaria en el tráfico mercantil contraponiéndolo a la seguridad que debía predominar en el tráfico civil ${ }^{30}$.

Pese a esta disparidad en ambos cuerpos normativos, la doctrina y la jurisprudencia se decantaron por la teoría del conocimiento que acogía el antiguo I 262 del Código Civil. Junto a ello se aplicaron también criterios de la teoría de la recepción para superar los inconvenientes de la cognición, que dejaba al arbitrio del oferente el momento de perfección del contrato en clara contradicción con el artículo I 256 del Código Civil ${ }^{31}$.

\footnotetext{
28. CAMACHO (2005) p. 298.

29. BERROCAL (2009) p. 32.

30. CAMACHO (2005) p. 299.

3 I. Artículo r 256 del CC: «La validez y el cumplimiento de los contratos no pueden dejarse al arbitrio de uno de los contratantes».
} 
Es evidente que en la época en que se dictó el Código Civil la regulación sobre contratos a distancia se refería principalmente a la contratación mediante correo epistolar, tal y como lo mencionaba de manera expresa la normativa. Pues bien, durante este período, es decir, previo a la promulgación de la LSSICE en el 2002, y gracias a los avances tecnológicos, comenzó a discutirse qué regla debía aplicarse para determinar el momento de la conclusión de los contratos electrónicos. La doctrina mayoritaria abogaba por la regla de la recepción, entendiendo perfeccionado el contrato cuando la aceptación llegaba al círculo de intereses del oferente ${ }^{32}$. Sin embargo, no faltaron voces, más atinadas, a juicio de González, que propusieron la asimilación de la contratación electrónica a la contratación epistolar, con el fin de aplicar también a aquéllas las reglas de los artículos I 262.2 del Código Civil y 54 del Código de Comercio, que entonces estaban vigentes ${ }^{33}$.

Con la promulgación de la LSSICE el panorama ha cambiado, sin embargo, ha generado nuevas encrucijadas que hasta el momento no han encontrado una solución uniforme en la doctrina.

En efecto, la LSSICE a través de su Disposición Adicional Cuarta realiza una importante modificación a los artículos I 262 del Código Civil y 54 del Código de Comercio estableciendo un régimen general unificado para la contratación civil y mercantil en materia de perfección de contratos a distancia.

El artículo I 262 del Código Civil pasa a quedar redactado del modo siguiente:

El consentimiento se manifiesta por el concurso de la oferta y la aceptación sobre la cosa y la causa que han de constituir el contrato.

Hallándose en lugares distintos el que hizo la oferta y el que la aceptó, hay consentimiento desde que el oferente conoce la aceptación, o desde que, habiéndosela remitido el aceptante, no pueda ignorarla sin faltar a la buena fe. El contrato, en tal caso, se presume celebrado en el lugar en que se hizo la oferta.

En los contratos celebrados mediante dispositivos automáticos, hay consentimiento desde que se manifiesta la aceptación.

32. GONZÁLEZ (2004) p. 232.

33. GONZÁLEZ (2004) p. 233. Según el autor, las reglas establecidas por los artículos r 262.2 del CC y 54 del CCo, aun cuando pudiera criticarse la disparidad de soluciones a que conducían, regían como norma general también a los contratos electrónicos, al menos en aquellos en que no intervinieran agentes inteligentes. 
De este modo, vemos que el párrafo primero del artículo I 262 del Código Civil mantiene la misma redacción anterior a la reforma. Por tanto, si existe coincidencia entre la oferta y la aceptación, surge el consentimiento, que por sí mismo basta para el nacimiento del contrato. Sin embargo, la reforma modifica el párrafo segundo del precepto en cuestión. La nueva redacción fija la regla general haciendo aplicable la teoría de la cognición para determinar el momento de perfección del contrato a distancia, independientemente del medio de comunicación que se utilice, aunque matizada con la de la recepción para el caso de existir mala fe ${ }^{34}$. De esta forma, el precepto resulta ser de adecuada aplicación a los nuevos medios de comunicación que son empleados en la contratación a distancia ${ }^{35}$.

El artículo I262.3, que regula los supuestos en que se haya celebrado un contrato mediante el uso de «dispositivos automáticos», estableció un régimen jurídico distinto, aplicando la teoría de la emisión para determinar el momento en que se perfecciona.

Con esto último se ha generado el mayor problema referente al tema tratado. Lamentablemente ni la LSSICE, en su anexo donde se dedicó a definir conceptos, ni el Código Civil, ni cuerpo normativo alguno, se encarga de definir qué se debe entender por "dispositivo automático", por tanto, si no se sabe con exactitud qué es un "dispositivo automático» tampoco se sabrá qué contratos son los concluidos a través de ellos y, con esto, existirá absoluta incerteza acerca de cuál teoría aplicar para determinar el momento en que se perfecciona un contrato a distancia.

\section{Los denominados dispositivos automáticos. La propuesta de solución}

Como ya hemos dicho anteriormente, el legislador no apunta ninguna definición de dispositivos automáticos en la LSSICE. El que sí hace referencia a

34. Según CAMACHO (2005), para un sector de la doctrina esta segunda matización del precepto adopta la teoría de la expedición o remisión. Sin embargo, en su opinión, esta nueva redacción, en conjunto, sigue las pautas doctrinales y jurisprudenciales ya establecidas, acoge como teoría general la de la recepción a fin de desvirtuar el sistema de la cognición. El contrato se entiende perfeccionado cuando el oferente ha conocido o podido conocer la aceptación, cuando no pueda ignorar dicha aceptación sin faltar a la buena fe.

35. CAMACHO (2005) p. 303. 
ellos es el Dictamen del Consejo de Estado que motivó dicha distinción, donde parece identificar a la contratación electrónica por dispositivos automáticos con la contratación realizada por página web mediante pedido electrónico, es decir, aquella en la que el consumidor remite pedido a través de la web mediante pulsación del botón que aparece en la misma página (página web activa). Seguidamente, el Consejo reconoce a estos supuestos como análogos a las denominadas «ventas automáticas».

En efecto, el referido dictamen señala lo siguiente:

Los supuestos en los que la aceptación de un contrato se manifiesta mediante un dispositivo automático instalado en la página web del oferente que puede ser accionado por el aceptante (lo que la doctrina anglosajona denomina «clickwraps») son análogos a las ventas automáticas ya conocidas en nuestro ordenamiento.

Respecto a la idea de considerar análogos los contratos celebrados mediante «dispositivos automáticos» a las llamadas «ventas automáticas», hacemos desde ya una precisión. La LOCM define la venta automática como: «forma de distribución detallista, en la cual se pone a disposición del consumidor el producto o servicio para que éste lo adquiera mediante el accionamiento de cualquier tipo de mecanismo y previo pago de su importe ${ }^{36}$. Pues bien, esta definición tiene como imagen inspiradora la adquisición de productos alimenticios, bebidas, tabaco, etcétera, por máquinas expendedoras, sin embargo, el contenido descriptivo del concepto permite la aproximación a otros sistemas de ventas que pueden interpretarse como automáticas. Aun aceptando esto, la aproximación a este fenómeno debe respetar una serie de notas características del concepto de venta automática. El caso de la contratación electrónica por página web no puede tener la consideración de venta automática, pero sí se puede considerar que, de forma análoga a la venta automática, la aceptación del pedido electrónico se realiza mediante una declaración de voluntad tácita o presunta al pulsar el botón de «aceptar» situado en la página web. De todas formas, y asumiendo que aun hay quienes postulan que dispositivo automático es asimilable a las ventas automáticas realizadas por máquinas expendedoras, cuestión que consideramos un error ${ }^{37}$, se debe tener claro que en la contrata-

36. Artículo 49 Ley 7/1996, de I 5 de enero, de Ordenación del Comercio Minorista. 37. En este sentido, FERNÁNDEZ (2003) p. 259. 
ción electrónica no concurre ninguna de las notas características de las ventas automáticas ${ }^{38}$.

Esta falta de definición ha llevado a la doctrina a considerar diversas interpretaciones acerca de lo que debe entenderse por dispositivo automático, sin que logren ponerse de acuerdo de forma unánime hasta el día de hoy.

Así, según lo reconoce González ${ }^{39}$, para un sector de la doctrina los contratos concluidos a través de un dispositivo automático serían los contratos electrónicos en general, sin distinción, es decir, aquellos en que tanto la oferta como la aceptación se transmiten por medio de equipos electrónicos de tratamiento y almacenamiento de datos, con independencia de que la contratación sea en línea (sirviéndose de la tecnología web o cualquier análoga) o fuera de línea (vía e-mail, por ejemplo). No concordamos con esta postura.

Otros equiparan la contratación celebrada mediante dispositivos automáticos a la contratación celebrada mediante página web. Se basan en el criterio establecido por el Consejo de Estado que interpreta que cuando la LSSICE hace referencia a los contratos celebrados mediante "dispositivos automáticos», en realidad se refiere a la contratación mediante página web con empleo de aceptación mediante pulsación del botón o clickwrap agreements en contraposición con los contratos electrónicos con empleo del correo electrónico. Se entiende que la expresión contratación celebrada por dispositivo automático es equivalente a la contratación electrónica mediante página web ${ }^{40}$. Esta solución permitiría que si el contrato mediante página web se perfecciona desde que se manifiesta la aceptación (teoría de la emisión según el I262.3 del CC)

38. La venta automática hace referencia a un tipo de contratación celebrada por medio de una declaración de voluntad tácita que supone que el consumidor del producto accione un mecanismo previo pago del mismo. La máquina es la que se encarga de distribuir el producto. Además, la adquisición que se prevé en la venta automática tiene un significado de realización inmediata de una prestación en favor del consumidor que no se da en la contratación electrónica. En ésta, por lo general, el producto o servicio no es suministrado de forma inmediata por el ordenador previo pago, aunque se puede entender como excepción la entrega online de productos digitales, dichas entregas no las suministra el ordenador que emplea el consumidor, sino, un tercero a través de su sitio web. Además en el caso de calificar la contratación electrónica como venta automática se produciría la exclusión de la aplicación de las normas sobre ventas a distancia.

39. GONZÁLEZ (2004) p. 236.

40. CAMACHO (2005) p. 330. 
el destinatario del servicio se libera de tener que probar que el prestador de servicios de la sociedad de la información recibió sus mensajes. En el mismo sentido se pronuncia Cavanillas ${ }^{41}$, quien señala que de acuerdo con los antecedentes legislativos de la LSSICE expuestos por el Dictamen del Consejo de Estado de 17 de enero de 2002, contratos celebrados a través de dispositivos automáticos son aquellos contratos electrónicos que no se concluyen mediante correo electrónico u otro tipo de comunicación electrónica equivalente. Está pensando en los contratos click, es decir, los celebrados online $e^{42}$.

Finalmente hay quienes equiparan la contratación por dispositivos automáticos a la contratación celebrada mediante agentes inteligentes o electrónicos. Parte de la doctrina considera que el artículo r 262.2 del Código Civil acoge el criterio de determinación del momento y lugar de perfección de los contratos celebrados entre personas distantes, independientemente del medio de comunicación empleado, incluyéndose los contratos electrónicos, celebrados mediante correo electrónico y mediante página web. En cuanto a qué contratos resultará aplicable el apartado $3 .^{\circ}$ del artículo i 262 que hace referencia a los contratos celebrados mediante dispositivos automáticos, se interpreta que se está haciendo referencia a los contratos celebrados con agentes inteligentes o electrónicos. Es decir, que cuando la LSSICE habla de contratos celebrados mediante dispositivos automáticos se está refiriendo a dispositivos previamente programados - agentes inteligentes - a los cuales ya nos hemos referido ${ }^{43}$.

Para Barral, el supuesto general de contratación electrónica que se pretende regular con la LSSICE, la contratación mediante página web, se someterá a la regla especial del artículo I 262.3 del Código Civil español (teoría de la emisión), cuando se trate de contratos celebrados mediante dispositivos automáticos, que en su opinión, son aquellos celebrados con agentes inteligentes, los denominados contratos click. En estos casos, el contrato se perfeccionará en el momento de la emisión de la aceptación, puesto que la recepción de la misma por el oferente se considera producida de forma instantánea. La autora seña-

4I. CAVANILLAS (2003) p. I95.

42. El autor va más allá, pues opina que la regla especial (art. I262.3 del CC.) sólo debería aplicarse a los contratos en que es el destinatario de un servicio de la sociedad de la información y no el prestador quien manifiesta su consentimiento, con lo que parece excluir el supuesto en el que el pedido del destinatario del servicio constituye la oferta.

43. CAMACHO (2005) p. 330-33I. 
la que a pesar de que en este caso el concurso de la oferta y la aceptación se mantienen dentro del supuesto de contratación a distancia por estricta falta de coincidencia en el espacio (no se encuentran físicamente presentes de manera simultánea), se habrá llevado a cabo mediante una comunicación ininterrumpida. Por su inmediatez se asimila a la contratación entre presentes, por lo que se le aplica la norma relativa a ésta ${ }^{44}$.

González postula la misma idea señalando que sólo cuando el prestador de servicios de la sociedad de la información opere a través de agentes inteligentes que procesen de forma automática los pedidos hechos por los clientes, lo que asegura es muy habitual ya que hoy las páginas web activas en su mayoría los utilizan, podrá entenderse que el contrato es de formación instantánea, porque tan pronto como el pedido del usuario llegue al servidor del prestador se tramitará informáticamente y se enviará una respuesta inmediata a aquél, quien, como seguirá conectado, podrá conocerla sin solución de continuidad, dándose la unidad de acto que caracteriza a la formación instantánea del contrato ${ }^{45}$.

En opinión de Camacho, con quien concordamos, la ratio legis determina que cuando el legislador se refiere a la contratación mediante dispositivos automáticos la identifica con la contratación mediante página web, aunque confunde la aparente automaticidad de este tipo de contratación con la automaticidad propia de la contratación mediante agente inteligente o dispositivo previamente programado ${ }^{46}$. La interactividad propia de las páginas web activas no siempre está relacionada con el empleo de agentes electrónicos ${ }^{47}$.

Aun concordando con la postura que sostiene que los contratos celebrados mediante «dispositivos automáticos» son aquellos en los cuales actúan «agentes inteligentes o electrónicos» y que, por tanto, los contratos celebrados a tra-

44. BARRAL (2003).

45. GONZÁLEZ (2004) p. 233.

46. El principal fundamento que lleva al Consejo de Estado a defender la adopción de un criterio diferente para determinar el momento de perfección del contrato por página web con dispositivos automáticos, parece ser la inmediatez de este tipo de ventas: «La inmediatez es característica de estas formas de contratación y resultaría sin duda contrario a la buena fe que quien instala, en condiciones de funcionamiento, un mecanismo automático de contratación pretendiera supeditar el perfeccionamiento del contrato o la prestación del consentimiento al momento en que tenga conocimiento efectivo de las aceptaciones formuladas por sus clientes».

47. CAMACHO (2005) p. 33 I. 
vés de una página web activa que opera mediante estos «agentes inteligentes» debe considerarse un contrato celebrado mediante "dispositivo automático", lo que hace aplicable la regla del supuesto especial del artículo I 262.3 haciendo prevalecer la teoría de la emisión para determinar el momento de la perfección del mismo, no podemos dejar de cuestionarnos ciertos puntos dudosos.

Tal como lo apuntamos anteriormente, la interactividad propia de las páginas web activas no está siempre relacionada con el empleo de agentes inteligentes. El usuario que remite el pedido de compra (entendiéndolo como un usuario medio, sin mayor conocimiento de informática ni derecho) mediante pulsación en el botón de aceptación situado en la página, recibiendo casi instantáneamente una confirmación de su tramitación, desconoce si en la contratación se ha empleado o no un agente electrónico. Camacho, incluso, haciendo alusión a este punto, sostiene que «no parece justificarse que para este tipo de contratación haya de establecerse un criterio específico porque justamente el usuario no tiene idea si está o no contratando con un agente inteligente ${ }^{48}$.

Imaginémonos que justo después de clickear el consumidor el botón de «aceptar» situado en la página web del oferente ocurre un imprevisto y se cae la señal del internet o hay un problema con los servidores, etcétera, provocando que esa aceptación no sea recibida por el prestador del servicio. Con la teoría de la emisión impuesta por el artículo I 262.3 del Código Civil, se entiende que el contrato se ha perfeccionado desde el momento en que el consumidor emite o manifiesta su aceptación, es decir, al pulsar el botón de «aceptar», sin importar o tener relevancia el hecho de que el prestador haya, siquiera, recibido dicha declaración de voluntad que contiene la aceptación. El consumidor y el prestador de servicios quedan obligados por ese contrato desde ese momento, sin embargo, el prestador no tuvo noticias de la aceptación y, por tanto, difícilmente cumplirá. Cabe recordar que la LSSICE en su artículo 28 obliga al oferente a confirmar la recepción de la aceptación mediante un acuse de recibo, pero no debe confundirse este simple deber poscontractual, que si no se cumple constituye una infracción leve o grave según sea el caso, con un requisito para la perfección misma del contrato ${ }^{49}$. El contrato ya se encuentra perfeccionado desde que se forma el consentimiento y éste se ha formado, en este caso, según el I262.3, en el momento en que el consumidor emite su aceptación clickeando el botón. ¿Cómo prueba el consumidor que efectivamente

48. Ídem.

49. RODRÍGUEZ (2006). 
pulsó el botón de aceptación y que, por tanto, el contrato quedó perfeccionado por ese solo hecho? ¿Cómo podía saber el consumidor que estaba contratando mediante una página web que utiliza un agente inteligente?

Refiriéndose al problema recién planteado, González manifiesta que si el pedido del destinatario es la aceptación y la procesa un agente electrónico, el contrato se considerará perfeccionado desde la manifestación de la aceptación, lo que no significa que sea suficiente la emisión, que ocurre cuando se presiona el botón o ícono habilitado para tal efecto por el oferente, sino que se requiere su expedición, es decir, que el mensaje de datos abandone la esfera de influencia del destinatario del servicio, lo que ocurrirá cuando ingrese en un sistema de información (un ordenador intermedio dentro de la cadena de ordenadores que conducirán la aceptación hasta el servidor del prestador de servicios) que esté fuera de su control. Lo que significa, agrega el autor, que cualquier fallo de conexión que se produzca antes de que la aceptación entre en un sistema de información ajeno al aceptante impedirá que el contrato se perfeccione. En cambio, si el error se produce en algún punto entre ese servidor ajeno al aceptante y al agente electrónico del oferente, el contrato deberá entenderse perfeccionado aunque la aceptación nunca haya llegado al servidor del prestador, lo haya hecho con retraso o no haya sido correctamente procesada por su agente. Por el contrario, si el pedido es la oferta o, siendo la aceptación, lo tramita el propio oferente o su representante, rige la regla general de la cognición atemperada en los mismos términos que si se hubiera comunicado la aceptación a través del correo electrónico o cualquier otro medio equivalente ${ }^{50}$.

A nuestro juicio, sin negar las virtudes de la teoría recién expuesta, consideramos que es contraria al tenor literal del artículo I262.3 del Código Civil que expresamente se refiere a la manifestación para determinar el momento en que se perfecciona un contrato celebrado por dispositivos automáticos. Cierto es que en la contratación vía página web activa se llega a confundir la emisión con la expedición pues el momento en que el consumidor manifiesta su aceptación, al mismo tiempo la está expidiendo al pulsar el botón, pero si el legislador hubiese preferido optar por la teoría de la expedición en este tipo de contratos, lo habría dicho expresamente.

Como se puede apreciar, en la contratación electrónica es fácil encontrarse con condicionantes operativos que deben ser convenientemente garantizados de cara a salvaguardar la confiabilidad de las transacciones electrónicas.

50. GONZÁLEZ (2004) p. 248. 
Tal vez sería necesario implementar un sistema a través de una comunicación informativa o logo distintivo para que todos los usuarios pudieran conocer si están contratando con una página web que utiliza agentes inteligentes o no y, en caso de ser afirmativo, explicar las consecuencias jurídicas que ese hecho apareja.

Galán postula que en estos casos no queda más remedio que acudir a determinadas tecnologías que eviten estos problemas, tales como el «sellado de tiempo» (o time stamping), como tecnología imprescindible para garantizar el momento exacto del intercambio de los mensajes entre ambos partícipes o la «custodia de declaraciones de voluntad», como elementos tecnológicos para el almacenamiento, custodia y puesta a disposición de las declaraciones de voluntad expresadas por los intervinientes en un contrato electrónico ${ }^{51}$.

\section{Conclusiones}

La generalización del uso de internet como forma de comunicación ha ofrecido también una nueva manera de contratar, esto es, la contratación electrónica. Evidentemente, como pudimos apreciar en el cuerpo del trabajo, la relevancia de determinar el momento exacto en que el contrato se perfecciona es importantísima, baste sólo con decir que es necesario conocerlo para saber desde cuándo se está obligado a cumplir con las obligaciones que emanan del contrato, para determinar desde cuándo se debe contar el plazo para ejercitar el derecho de desistimiento, para saber cuándo se puede retirar o revocar la oferta y la aceptación, resulta esencial para determinar la capacidad de las partes contratantes, para conocer la norma aplicable en supuestos de modificaciones legislativas, para establecer el límite de retroactividad del contrato sometido a condición suspensiva, para determinar si existe o no la posibilidad de rescindir los contratos celebrados en fraude de los acreedores, etcétera.

Demás está decir que la idea no es desincentivar la contratación electrónica porque eso sería contraproducente y poco realista, al contrario, nuestra pretensión con el trabajo desarrollado era, justamente, demostrar la importancia que tiene dicha contratación en la actualidad y para ello consideramos esencial tratar de dilucidar la encrucijada que se plantea respecto del momento de perfección del contrato y, de esta forma, dotar al sistema de mayor seguridad jurídica debida y mayor protección de los consumidores y generar la confianza

5I. GALÁN (2004) p. 22 I-222. 
suficiente por parte de éstos para con el sistema electrónico de contratación, con el fin de que se transforme en un instrumento idóneo, eficaz y confiable para realizar transacciones con el correspondiente ahorro de tiempo, recursos y energía.

Compartiendo la opinión de algunos autores, sostenemos que un contrato celebrado mediante dispositivos automáticos es aquel en el cual el consumidor (pensando en la contratación business to consumer) contrata con un agente inteligente, es decir, con un soporte de ordenador previamente programado. Asimismo, cuando se contrata a través de una página web activa (piénsese hoy en día en las denominadas web 2.0), se está contratando con estos agentes inteligentes y, por tanto, mediante «dispositivos automáticos», lo que hace aplicable la teoría de la emisión, manifestación o declaración para determinar el momento de la perfección de dicho contrato según lo dispuesto por el artículo I 262.3 del Código Civil español.

De todas formas, somos conscientes que, aunque ésta parece ser la solución más adecuada, no está exenta de problemas y críticas, sobre todo en materia probatoria y de protección de los derechos del consumidor en caso de fallos del sistema, como quedó de manifiesto a lo largo de la investigación expuesta.

\section{Referencias}

BARRAL, Immaculada. La regulación del comercio electrónico. Madrid: Dykinson, 2003. $207 \mathrm{p}$.

BARRAL, Inmaculada. La contratación por vía electrónica: adaptación del marco jurídico mediante los principios de equivalencia funcional. En LLAMAS POMBO, Eugenio (Dir.) Estudios de derecho de obligaciones: homenaje al profesor Mariano Alonso Pérez, vol. 1. Madrid: Ed. La Ley, 2006. p. IO7-I 24.

BARRIUSO, Carlos. La contratación electrónica. Madrid: Dykinson, 2006. $780 \mathrm{p}$.

BERROCAL, Ana. Perfección del contrato en la ley 24/2002, de 11 de julio de servicios de la sociedad de la información y de comercio electrónico: la unificación de criterios. En Revista de contratación electrónica, $\mathrm{N}^{\mathrm{o}}$ Io०, enero 2009. Disponible en: [http://www.vLex.es].

CAMACHO, Sandra. Partes intervinientes, formación y prueba del contrato electrónico. Madrid: Reus, 2005. 527 p.

CLEMENTE, Mario y CAVANILLAS, Santiago. Responsabilidad civil y con- 
tratos en internet. Su regulación en la Ley de Servicios de la Sociedad de la Información y de Comercio Electrónico. Granada: Comares, 2003. 20I p. DÍEZ-PICAZO, Luis. Fundamentos de derecho civil patrimonial (Tomo I, Introducción y teoría del contrato). Sexta edición. Navarra: Thomson Civitas, 2007. $347 \mathrm{p}$.

FERNÁNDEZ, María Ángeles. Comentario al artículo 1262 del Código Civil tras la reforma introducida por la Ley 34/2002 de 11 de julio, de servicios de la sociedad de la información y de comercio electrónico. En Actualidad Civil, $\mathrm{N}^{\mathrm{o}}$ Io, Sección Legislación Comentada, Tomo I, Editorial La Ley, Marzo 2003. Disponible en: [http://www.laley.es].

GALÁN, Carlos. Consentimiento prestado por medios electrónicos (la contratación electrónica), en ESCOLANO, José Javier (Dir.). Nuevas tecnologías en la contratación: sociedad, nueva empresa e hipoteca electrónica. Navarra: Thomson Civitas, 2005. p. 204-228.

GONZÁLEZ, Alfonso. La formación del contrato tras la Ley de servicios de la sociedad de la información y de comercio electrónico. Granada: Editorial Comares, 2004. 265 p.

GUISADO, Ángela. Formación y perfección del contrato en Internet. Madrid: Marcial Pons, 2004. 229 p.

MENÉNDEZ, Juan Carlos. El contrato vía Internet. Barcelona: J. M. Bosch Editor, 2005. $444 \mathrm{p}$.

PARDO, José Ricardo. Las páginas web como soporte de condiciones generales contractuales. Navarra: Thomson Aranzadi, 2003. I62 p.

PINOCHET, Ruperto. La formación del consentimiento a través de las nuevas tecnologías de la información. Parte III: El momento de formación del consentimiento electrónico. En Revista Ius et Praxis, vol. I , $\mathrm{N}^{\circ}$ 2. Talca: Facultad de Ciencias Jurídicas y Sociales Universidad de Talca, 2005. p. 273-302.

RODRÍGUEZ, Concepción. Oferta, aceptación y perfección en los contratos celebrados mediante dispositivos automáticos. En Actualidad Civil, $\mathrm{N}^{\circ}$ I 2, Sección a fondo, Tomo I, Editorial La Ley, junio 2006. Disponible en: [http://www.laley.es].

VEGA, Antonio. Contratos electrónicos y protección de los consumidores. Madrid: Reus, 2005. 495 p. 